\title{
Evaluation of cardiovascular disease in patients with systemic arterial hypertension in relation to age and sex: a retrospective study in a south Indian population
}

\author{
Avaliação de doença cardiovascular em pacientes com hipertensão arterial sistêmica \\ em relação a idade e sexo: estudo retrospectivo em uma população do sul da Índia
}

Ashwini Aithal Padur', Aisyah binti Hamdan², Talissa Tatiana binti Intisar Patrick Abdullah², Chandrigga Gunalan², Naveen Kumar

\begin{abstract}
Background: Systemic arterial hypertension manifests as constant elevation of blood pressure and is considered to be an important cardiovascular risk factor. Systemic evaluation of cardiovascular diseases in patients with systemic arterial hypertension is imperative for prevention. Objectives: The objective of the present study was to investigate and inter-relate sex and age with systemic arterial hypertension and cardiovascular diseases. Methods: Medical records of patients with systemic arterial hypertension and cardiovascular disease were evaluated. Data from the medical records were recorded in a prescribed protocol and the data were analyzed and correlated to the patients' age and sex. Results: A total of 170 medical records for patients who visited the cardiology department were reviewed. Of these, 50 patients had systemic arterial hypertension and 19 of this subset had cardiovascular diseases. When we correlated systemic arterial hypertension with age, we observed that patients in the 51-60 years age group were more prone to systemic arterial hypertension (36\%). Most of the patients with both systemic arterial hypertension and cardiovascular disease were female and in the 61-70 years age group, while among males the highest rate of occurrence was seen in the 51-60 years age group. The correlation coefficient ( $r$ ) was 0.62 , indicating a moderate, positive, linear relationship between systemic arterial hypertension and cardiovascular disease. Conclusions: A majority of patients with systemic arterial hypertension may develop cardiovascular disease and, as age increases, the tendency to develop hypertension also increases.
\end{abstract}

Keywords: hypertension; cardiovascular disease; risk factors; retrospective study.

\begin{abstract}
Resumo
Contexto: A hipertensão arterial sistêmica se manifesta como elevação constante da pressão sanguínea e é considerada um importante fator de risco cardiovascular. A avaliação sistêmica de doenças cardiovasculares em pacientes com hipertensão arterial sistêmica é crucial para a prevenção. Objetivos: O objetivo deste estudo foi investigar e inter-relacionar sexo e idade com hipertensão arterial sistêmica e doença cardiovascular. Métodos: Prontuários médicos de pacientes com hipertensão arterial sistêmica e doença cardiovascular foram avaliados. Dados dos prontuários médicos foram lançados em um protocolo pré-definido, e os dados foram analisados e correlacionados com a idade e o sexo dos pacientes. Resultados: Um total de 170 prontuários de pacientes que visitaram o departamento de cardiologia foram revisados. Destes, 50 pacientes apresentavam hipertensão arterial sistêmica, e destes, 19 tinham doença cardiovascular. Ao correlacionar hipertensão arterial sistêmica com idade, observamos que pacientes do grupo etário de 51-60 anos estavam mais suscetíveis a apresentar hipertensão arterial sistêmica (36\%). A maioria dos pacientes com hipertensão arterial sistêmica e doença cardiovascular era do sexo feminino e estava no grupo etário de 61-70 anos; já entre os pacientes do sexo masculino, a maior taxa de ocorrência foi no grupo etário de 51-60 anos. O coeficiente de correlação (r) foi 0,62, indicando uma relação moderada, positiva, linear entre hipertensão arterial sistêmica e doença cardiovascular. Conclusões: A maioria dos pacientes com hipertensão arterial sistêmica pode desenvolver doença cardiovascular; conforme a idade aumenta, também cresce a tendência a desenvolver hipertensão.
\end{abstract}

Palavras-chave: hipertensão; doença cardiovascular; fatores de risco; estudo retrospectivo.

\footnotetext{
${ }^{1}$ Manipal University, Melaka Manipal Medical College, Department of Anatomy, Manipal Campus, Manipal, Karnataka, India.

${ }^{2}$ Manipal University, Melaka Manipal Medical College, Manipal Campus, Manipal, Karnataka, India.

Financial support: None.

Conflicts of interest: No conflicts of interest declared concerning the publication of this article

Submitted: November 30, 2016. Accepted: January 24, 2017.
}

The study was carried out at Manipal University, Melaka Manipal Medical College, Manipal Campus, Manipal, Karnataka, India. 


\section{INTRODUCTION}

Blood pressure is defined as the lateral pressure exerted by the column of blood on the walls of the arteries. It usually means arterial pressure, which is recorded in millimeters of mercury - for example $120 / 80 \mathrm{mmHg}$. The higher number denotes the systolic pressure while the lower number denotes the diastolic pressure. ${ }^{1}$ High blood pressure, or systemic arterial hypertension (SAH), is seen when blood pressure is constantly elevated and is considered an important cardiovascular risk factor. A study involving 52 countries all over the world showed that SAH is considered a greater relative risk factor for acute myocardial infarction than diabetes mellitus (DM). ${ }^{2}$ It has been observed that as age advances, the risk of developing SAH and cardiovascular disease (CVD) also increases. The blood vessels lose their flexibility with age, which can contribute to increased pressure throughout the system. Extensive epidemiologic studies have provided evidence that SAH accelerates development and progression of atherosclerosis, leading to CVD.

Both prevalence and incidence of CVD are increasing in the developing world. ${ }^{3}$ This may be due to the swift socioeconomic growth in developing countries and increasing exposure to CVD risk factors such as DM, $\mathrm{SAH}$, hypercholesterolemia, and smoking. There are often no warning signs or symptoms of SAH and so many people are not aware of it. Although there have been improvements in prevention, treatment, and control of SAH, it still remains an important public health challenge. Onset of SAH and its effect on CVD may be modulated by various environmental and genetic factors. It has been postulated that socioeconomic, environmental, and genetic factors play an influential role in the development of CVD. ${ }^{4}$ The Indian population is believed to have higher risk and prevalence of CVD when compared to other ethnic groups. ${ }^{5}$ India is said to have 29.8 million symptomatic patients with CVD, 19.3 million diabetics, and 118 million hypertensive patients, who are at great risk of developing CVD. ${ }^{6}$ Despite the high rates of occurrence, there is very limited data regarding the correlation between the occurrence of CVD in hypertensive patients in India and its relation to sex and age.

The objectives of this study were therefore to investigate the occurrence of CVD in patients with SAH from a South Indian population, by retrospective evaluation, to investigate the relationships between sex, age, and SAH, and to inter-relate these factors with CVD.

\section{MATERIALS AND METHOD}

\section{Data collection}

This retrospective study was conducted at the Dr. T.M.A Pai Hospital, a primary tertiary care teaching hospital in Udupi district of Karnataka state, India. Human research ethics committee clearance was obtained prior to data collection (IEC 322/2015). Medical records from the past five years for patients with SAH who had CVD were collected from the medical records section of the hospital. Patients' details were kept confidential and prior permission was obtained from the patients and their families. No interventions were performed. All relevant clinical and laboratory data was documented on a prescribed protocol. Patients' demographic data, duration of hospital stay, type of CVD, whether or not they had diabetes, and smoking and drinking habits were noted. All relevant information was noted from eligible patients' files based on the inclusion and exclusion criteria (Table 1). A total of 170 medical records for patients who had visited the cardiology department were reviewed.

\section{Data analysis}

The data collected were classified according to whether or not patients had SAH. Records for patients who had SAH and CVD were then selected and analyzed. They were then correlated to patient age and sex. A Spearman correlation coefficient $[\mathrm{r}]$ was calculated using the values of the two variables (SAH and CVD) to determine whether they were associated. The data were analyzed using SPSS (version 16.0) software.

\section{RESULTS}

Of the total of 170 cases, 50 patients had SAH $(29 \%)$ without any other illnesses diagnosed that are not related to cardiology and all were more than 20 years old. We excluded other records because the patients had SAH associated with other diseases.

Table 1. Inclusion and exclusion criteria for data collection.

\begin{tabular}{ll}
\hline \multicolumn{1}{c}{ Inclusion criteria } & \multicolumn{1}{c}{ Exclusion criteria } \\
\hline Age under 70 years & Age over 70 years \\
\hline Patients with hypertension & $\begin{array}{l}\text { Patients without hypertension } \\
\text { having cardiovascular disease }\end{array}$ \\
\hline Patients having only & $\begin{array}{l}\text { Patients with any infectious } \\
\text { disease and with congenital } \\
\text { cardiovascular diseases }\end{array}$ \\
\hline Patients who are non-diabetic & $\begin{array}{l}\text { Patients having cardiovascular } \\
\text { diseases associated with other } \\
\text { diseases }\end{array}$ \\
\hline
\end{tabular}


Of the remaining 50 patients, 27 were female and 23 were male.

Nineteen of the patients with SAH had CVD (38\%), while 31 of them did not have any CVD $(62 \%)$ associated with SAH (Figure 1). This shows that $\mathrm{SAH}$ is one of the main risk factors of CVD. Upon evaluation of the trend of SAH against age, it was observed that patients in the 51-60 years age group were most prone to $\mathrm{SAH}(36 \%)$, followed by patients in the $61-70$ years (34\%), $41-50$ years $(18 \%)$, $31-40$ years $(8 \%)$, and $21-30$ years (4\%) age groups (Table 2 and Figure 2). This shows that the frequency of SAH increases as age advances.

When we related SAH to sex we observed that the prevalence was higher among females (54\%) than among males (46\%). Most of the female patients with SAH and CVD were in the 61-70 years age group, while among males the highest rate of occurrence was seen in the 51-60 years age group. The lowest frequency was seen in the 21-40 years age group (Figure 3 and Table 3).

The Spearman correlation coefficient $(r)$ for incidences of SAH and CVD showed a moderate, positive, linear relationship ( $\mathrm{r}=2)$. This clearly indicates that SAH and CVD are significantly related to each other, which is a very important finding.

\section{DISCUSSION}

Systemic arterial hypertension is diagnosed based on elevation of either systolic or diastolic blood pressure and the objective of hypertension management is to attain normalization of both. There is a strong and frequent association between SAH and CVD. Cardiovascular diseases are diseases in which several factors such as smoking, dyslipidemia, SAH, DM, obesity, and hereditary factors play major roles. According to

Table 2. Relation between age and hypertension prevalence.

\begin{tabular}{cc}
\hline Age (in years) & No. of patients with hypertension $(\mathbf{n}=\mathbf{5 0})$ \\
\hline $21-30$ & $2(4 \%)$ \\
$31-40$ & $4(8 \%)$ \\
$41-50$ & $9(18 \%)$ \\
$51-60$ & $18(36 \%)$ \\
$61-70$ & $17(34 \%)$ \\
\hline
\end{tabular}

Table 3. Interrelation between hypertension and cardiovascular disease, by patient age and sex.

\begin{tabular}{|c|c|c|c|c|c|c|}
\hline \multirow{2}{*}{ Sex } & \multicolumn{5}{|c|}{ Age (in years) } & \multirow{2}{*}{$\begin{array}{c}\text { Total } \\
\text { number }\end{array}$} \\
\hline & $21-30$ & $31-40$ & $41-50$ & $51-60$ & $61-70$ & \\
\hline Male & 1 & 1 & 1 & 3 & 1 & $7(46 \%)$ \\
\hline Female & 0 & 0 & 1 & 2 & 9 & $12(54 \%)$ \\
\hline
\end{tabular}

reports, cardiovascular deaths cause $34 \%$ of global mortality in women and $28.2 \%$ of all deaths in men and are affect all sections of the society. ${ }^{7}$ It has been reported that CVD manifest almost a decade earlier in the Indian subcontinent when compared to the West. ${ }^{8}$ Additionally, it is stated that deaths related to CVD have been found to occur 5-10 years earlier in the Indian subcontinent than in Western countries. ${ }^{9}$

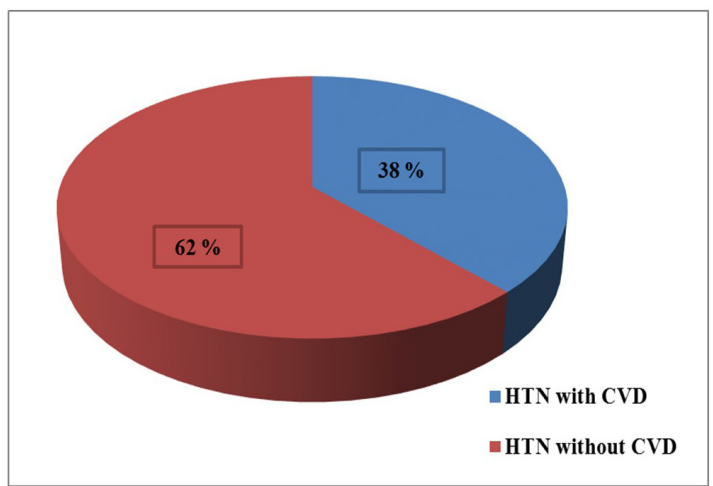

Figure 1. Relation between hypertension (HTN) and cardiovascular disease (CVD).

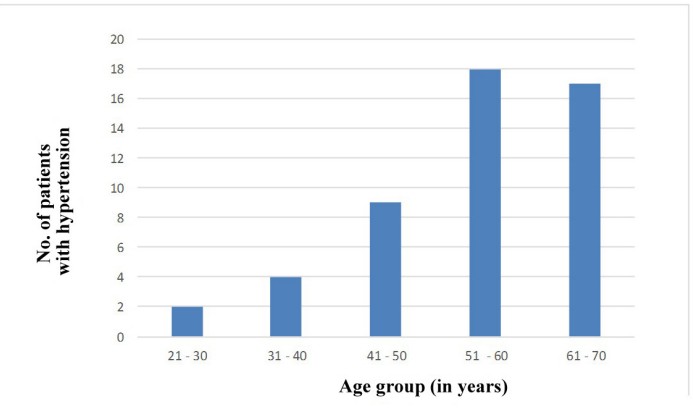

Figure 2. Graph showing relation (in percentage) between age and hypertension.

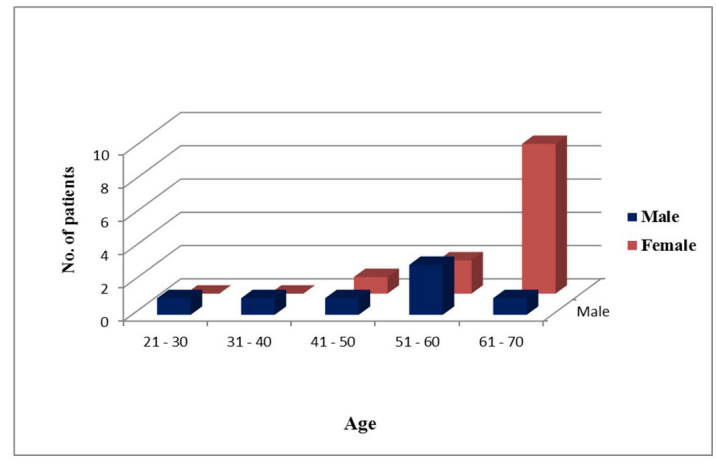

Figure 3. Graph showing the interrelation (in percentage) between hypertension (HTN) and cardiovascular disease (CVD), by patient age and sex. 
This shows that the rise in the prevalence of CVD is a reality that is becoming increasingly evident in India.

Systemic arterial hypertension is considered to be a major risk factor in recent years since patients with SAH have two times greater chances of getting CVD. In clinical practice, treatment of high blood pressure is focused on achieving health benefits for patients, whereas public health is focused on prevention of high blood pressure and to reduce the incidence of coronary heart disease in populations. ${ }^{10} \mathrm{~A}$ study by Razia et al., found that the percentage occurrence of CVD in the population studied was $57.3 \%$ and $42.2 \%$ of these were SAH patients. ${ }^{11}$ In our study, we found that $38 \%$ of the patients with SAH, had CVD, which demonstrates a high prevalence. The onset of SAH is mostly beyond the third decade of life; probably due to arterial stiffening and loss of arterial compliance that occurs with aging and other factors. ${ }^{12}$ This was also evident in our study, since we observed that patients in the 51-60 years age group are more prone to $\mathrm{SAH}$ (36\%), followed by patients in the $61-70$ years $(34 \%)$ and $41-50$ years $(18 \%)$ age groups.

In terms of its relation to sex, while men are said to be predominantly affected by $\mathrm{SAH}$, women are also no longer considered immune to its occurrence. ${ }^{13}$ According to Kannel, SAH was found to account for $39 \%$ of cases in men and $59 \%$ in women. ${ }^{14}$ Our observations were similar, since in our study population SAH associated with occurrence of CVD was higher in female patients (54\%) than in male patients $(46 \%)$ and the female patients were in the of 50-70 years age group. This is a very important observation and few studies have linked this occurrence to hormonal response. It has been stated that the risk of developing CVD in hypertensive compared with non-hypertensive individuals is about twofold in men and threefold in women. ${ }^{15}$ This is partly explained by early menopause in Indian women, which to a great extent reduces the protective effect of oestrogens. ${ }^{16}$

In recent years, infectious diseases have become relatively less of a concern, while chronic diseases like CVD continue to plague the global population. It has also been noted that most of these diseases are largely related to lifestyle factors, and can be minimized or prevented by lifestyle changes. This would be the most appropriate method to deal with SAH and CVD-related mortality and morbidity. Several evidence-based studies have constantly indicated a positive correlation between physical activity and good health. People who tend to have sedentary lifestyles risked an increase in blood pressure over time, whereas those who were physically active seemed to avoid this adverse effect. ${ }^{17}$ Implementing simple but effective strategies for prevention of CVD is conspicuously obvious. Therefore, there is very little actual research done in these areas in India. ${ }^{18,19}$ Preventive measures require multidisciplinary, multi-sectorial, and multi-level co-ordination and approaches that address the patient, provider, healthcare systems, public health, and public policy for the prevention and control of CVD in India. ${ }^{20}$

\section{CONCLUSION}

The present study revealed that there exists a positive and significant relationship between CVD and $\mathrm{SAH}$ and that $\mathrm{SAH}$ is a major risk factor of $\mathrm{CVD}$.

\section{REFERENCES}

1. Hall JE, Guyton AC. Guyton and Hall textbook of medical physiology. 12th ed. Philadelphia: Saunders Elsevier; 2011. 224 p.

2. Yusuf PS, Hawken S, Ôunpuu S, et al. Effect of potentially modifiable risk factors associated with myocardial infarction in 52 countries (the INTERHEART study): case control study. Lancet. 2004;364(9438):937-52. PMid:15364185. http://dx.doi.org/10.1016/ S0140-6736(04)17018-9.

3. Okrainec K, Banerjee DK, Eisenberg MJ. Coronary artery disease in the developing world. Am Heart J. 2004;148(1):7-15. PMid:15215786. http://dx.doi.org/10.1016/j.ahj.2003.11.027.

4. Milane A, Abdallah J, Kanbar R, et al. Association of hypertension with coronary artery disease onset in the Lebanese population. Springerplus. 2014;3(1):533. PMid:25279324. http://dx.doi. org/10.1186/2193-1801-3-533.

5. YusufS, Reddy S, Ounpuu S, Anand S. Global burden of cardiovascular diseases: part II: variations in cardiovascular disease by specific ethnic groups and geographic regions and prevention strategies. Circulation. 2001;104(23):2855-64. PMid:11733407. http://dx.doi. org/10.1161/hc4701.099488.

6. Aggarwal A, Aggarwal S, Sharma V. Metabolic syndrome and coronary artery disease in Indians younger than 40 years. Endocrinol Metab. 2012;2:39-45

7. World Health Organization. The World Health Report 1999 making a difference. Geneva: World Health Organization; 1999.

8. Gupta R. Burden of coronary heart disease in India. Indian Heart J. 2005;57(6):632-8. PMid:16521628.

9. Joshi P, Islam S, Pais P, et al. Risk factors for early myocardial infarction in South Asians compared with individuals in other countries. JAMA. 2007;297(3):286-94. PMid:17227980. http:// dx.doi.org/10.1001/jama.297.3.286.

10. Van den Hoogen PC, Seidell JC, Menotti A, Kromhout D. Blood pressure and long term coronary heart disease mortality in the Seven Countries Study: implications for clinical practice and public health. Eur Heart J. 2000;21(20):1639-42. PMid:11032686. http:// dx.doi.org/10.1053/euhj.2000.2270.

11. Iqbal R, Ahmad Z, Malik F, et al. A statistical analysis of hypertension as cardiovascular risk factor. Middle East J Sci Res. 2012;12(1):19-22.

12. Blair DA, Glover WE, Greenfield AD, Roddie IC. Excitation cholinergic vasodilator nerves to human skeletal muscles during emotional stress. J Physiol. 1959;148(3):633-47. PMid:13801238. http://dx.doi. org/10.1113/jphysiol.1959.sp006312. 
13. Aggarwal A, Aggarwal S, Goel A, Sharma V, Dwivedi S. A retrospective case control study of modifiable risk factors and cutaneous markers in Indian patients with young coronary artery disease. JRSM Cardiovasc Dis. 2012;1(3).

14. Kannel WB. Fifty years of framingham study contributions to understanding hypertension. J Hum Hypertens. 2000;14(2):83-90. PMid:10723112. http://dx.doi.org/10.1038/sj.jhh.1000949.

15. Levy D, Larson MG, Vasan RS, Kannel WB, Ho KK. The progression from hypertension to congestive heart failure. JAMA. 1996;275(20):1557-62. PMid:8622246. http://dx.doi.org/10.1001/ jama.1996.03530440037034.

16. Fuster V, Pearson TA. 27th Betheseda Conference. Matching the intensity of risk factor management with the hazard of coronary heart disease events. J Am Coll Cardiol. 1996;27:957-1047. PMid:8609361.

17. Buttar HS, Li T, Ravi N. Prevention of cardiovascular diseases: role of exercise, dietary interventions, obesity and smoking cessation. Exp Clin Cardiol. 2005;10(4):229-49. PMid:19641674.

18. Prabhakaran P, Ajay VS, Prabhakaran D, et al. Global cardiovascular disease research survey. J Am Coll Cardiol. 2007;50(24):2322-8. PMid:18068042. http://dx.doi.org/10.1016/j.jacc.2007.08.040.

19. Bala A, Gupta BM. Mapping of Indian neuroscience research: a scientometric analysis of research output during 1999-2008. Neurol India. 2010;58(1):35-41. PMid:20228461. http://dx.doi. org/10.4103/0028-3886.60393.

20. Prabhakaran D, Yusuf S. Cardiovascular disease in India: lessons learnt \& challenges ahead. Indian J Med Res. 2010;132(5):529-30. PMid:21150004.
Correspondence

Naveen Kumar

Manipal University, Melaka Manipal Medical College, Department of Anatomy

Madhav Nagar - Manipal 576104 - Karnataka State, India E-mail: naveentonse@gmail.com

Author information

AAP and NK - Department of Anatomy, Melaka Manipal Medica College, Manipal Campus, Manipal University. ABH, TTBIPA and CG - Bachelors in Medicine and Bachelors in Surgery (MBBS) students, Melaka Manipal Medical College, Manipal Campus, Manipal University.

Author contributions Conception and design: AAP, NK Analysis and interpretation: AAP, ABH, TTBIPA, CC Data collection: $A B H, T T B I P A, C C$ Writing the article: AAP ABH, TTBIPA, CC Critical revision of the article: AAP, NK Final approval of the article*: AAP, ABH, TTBIPA, CG, NK Statistical analysis: AAP Overall responsibility: NK

*All authors have read and approved of the final version of the article submitted to J Vasc Bras. 